Check for updates

Cite this: RSC Adv., 2019, 9, 21608

Received 24th April 2019

Accepted 28th June 2019

DOI: 10.1039/c9ra03046h

rsc.li/rsc-advances

\section{Tremella-like NiO microspheres embedded with fish-scale-like polypyrrole for high-performance asymmetric supercapacitor $\dagger$}

\author{
Kehui Han, ${ }^{a}$ Yan Liu, ${ }^{\text {ab }}$ Hui Huang, ${ }^{a}$ Qinghua Gong, ${ }^{a}$ Zhiliang Zhang ${ }^{a}$ \\ and Guowei Zhou (D) *a
}

\begin{abstract}
Tremella-like $\mathrm{NiO}$ microspheres embedded with fish-scale-like polypyrrole (PPy) were synthesized by polymerizing pyrrole (Py) onto uniform $\mathrm{NiO}$ nanosheets. PPy has a fish-scale-like appearance with a thickness of approximately $10 \mathrm{~nm}$, and is connected to the $\mathrm{NiO}$ nanosheet surface. NiO/PPy microspheres (diameter of $\sim 4 \mu \mathrm{m}$ ) were applied as the electrode material in a supercapacitor. The $\mathrm{NiO} /$ PPy- 6 obtained under a NiO : Py molar ratio of 6 shows a high specific capacitance of $3648.6 \mathrm{~F} \mathrm{~g}^{-1}$ at $3 \mathrm{~A} \mathrm{~g}^{-1}$ and good rate capability (1783 $\mathrm{F} \mathrm{g}^{-1}$ at a high current density of $30 \mathrm{~A} \mathrm{~g}^{-1}$ ). An asymmetric supercapacitor (ASC) was fabricated using $\mathrm{NiO} / \mathrm{PPy}-6$ and activated carbon (AC) as the positive electrode and the negative electrode, respectively. NiO/PPy-6//AC can achieve a high specific capacitance of $937.5 \mathrm{~F} \mathrm{~g}^{-1}$ at $3 \mathrm{~A} \mathrm{~g}^{-1}$ and a high energy density of $333.3 \mathrm{~W} \mathrm{~h} \mathrm{~kg}^{-1}$ at a power density of $2399.99 \mathrm{~W} \mathrm{~kg}^{-1}$. The excellent supercapacitor performance is assigned to the combined contribution of both components and the unique heterostructure in NiO/PPy-6.
\end{abstract}

\section{Introduction}

In modern society, energy conversion and reserves have become important concerns. ${ }^{1,2}$ The design and fabrication of supercapacitors have recently become hot topics in research owing to the materials' excellent energy density, superior reversibility, and high specific capacitance..$^{3-6}$ Electrode materials play an important role in the development of supercapacitors; ${ }^{7}$ in particular, electrode materials used for supercapacitors have three varieties, namely, carbon, polymer, and metal oxides. ${ }^{8}$ The poor conductivity of carbon materials often limits their applications. Accordingly, as typical electrode materials with Faraday pseudocapacitance, metal oxides and conductive polymers are widely used in the field of supercapacitors. ${ }^{9}$

${ }^{a}$ Key Laboratory of Fine Chemicals in Universities of Shandong, School of Chemistry and Pharmaceutical Engineering, Qilu University of Technology (Shandong Academy of Sciences), Jinan 250353, P. R. China.E-mail: gwzhou@qlu.edu.cn; guoweizhou@ hotmail.com

${ }^{b}$ Zaozhuang Vocational College of Science \& Technology, Tengzhou 277500, P. R. China

$\dagger$ Electronic supplementary information (ESI) available: Fig. S1 FESEM images of $\mathrm{Ni}_{3}\left(\mathrm{NO}_{3}\right)_{2}(\mathrm{OH})_{4}$ precursors; Fig. S2 XRD images of $\mathrm{Ni}_{3}\left(\mathrm{NO}_{3}\right)_{2}(\mathrm{OH})_{4}$ precursors; Fig. S3 (a) $\mathrm{N}_{2}$ adsorption-desorption isotherms of $\mathrm{NiO}$ and NiO/PPy (b) the pore size distribution of NiO and NiO/PPy; Fig. S4 (a) specific capacitance of NiO and NiO/PPy; (b) Nyquist plots of NiO and NiO/PPy; Fig. S5 (a) CV curves of the AC at different scan rates; (b) GCD curves of the AC at different current densities; Fig. S6 (a) CV curves of NiO//AC at different scan rates; (b) GCD curves of $\mathrm{NiO} / / \mathrm{AC}$ at different current densities; Table S1 comparison of synthesis methods, morphology, and electrochemical performances of different $\mathrm{NiO}$ composite electrodes. See DOI: 10.1039/c9ra03046h
Metal oxides, as electrode materials for supercapacitors, have received considerable attention owing to their high theoretical energy density, low cost, and low environmental impact. Metal oxides yield specific capacities far below their theoretical values. The rate and cycling performances of metal oxides are also inferior because of poor conductivity and instability during charging/discharging. ${ }^{10,11}$ Therefore, the preparation of metal oxide composites with excellent properties is needed to improve the performance of metal oxides. ${ }^{12}$ These composites should exhibit good electrical conductivity and produce new electrochemical properties. ${ }^{13}$

Polypyrrole (PPy), polyaniline, polyacetylene, polyparaphenylene, and polythiophene are members of a class of organic polymers with high conductivity, and have become hotspots in material science research. ${ }^{14,15}$ Among these polymers, PPy is a $\pi$-bond macromolecular chain structure composed of single and double bonds. ${ }^{16}$ The conjugated structure enables PPy to have good charge transport capability. ${ }^{17}$ As a supercapacitor electrode material, PPy can exhibit a capacitance of 200-500 F $\mathrm{g}^{-1} \cdot{ }^{18,19}$ Pure PPy has many advantages, such as large surface area, high capacitance, and chemical stability. However, PPy is rigid and difficult to dissolve in common organic solvents (i.e., ethanol and acetone), has poor mechanical ductility, and is difficult to process into desired products. ${ }^{20}$

Considering that PPy and metal oxides have their benefits and drawbacks, several composites, such as $\mathrm{Co}_{3} \mathrm{O}_{4} / \mathrm{PPy},{ }^{21-24}$ $\mathrm{Fe}_{3} \mathrm{O}_{4} / \mathrm{PPy},{ }^{25-27} \mathrm{SnO}_{2} / \mathrm{PPy},{ }^{28} \mathrm{NiCo}_{2} \mathrm{~S}_{4} / \mathrm{PPy},{ }^{15} \mathrm{CoSe}_{2} / \mathrm{PPy}{ }^{29}$ and $\mathrm{VO}_{2} /$ $\mathrm{PPy}^{30}$ were synthesized. However, many factors, including a complex preparation process and high cost, impede the 
application of these materials. ${ }^{\mathbf{1 9 , 2 0}}$ Owing to the wide range of resources, low cost, and benign environmental impact of $\mathrm{NiO}$, this material has become well known as a supercapacitor material, in which the theoretical capacitance can reach $3230 \mathrm{~F} \mathrm{~g}^{-1}$ at voltages ranging from $0 \mathrm{~V}$ to $0.4 \mathrm{~V}{ }^{1}$ Several researchers have studied NiO/PPy composites. Fu et al. ${ }^{31}$ synthesized a flower-like $\mathrm{NiO} / \mathrm{PPy}$ composite by a two-step process. NiO was prepared by using $\mathrm{Ni}(\mathrm{OH})_{2}$ as the precursor, and then Py was polymerized on its surface. The specific capacitance of the resulting composite was low. However, this value can be increased by regulating the amount of PPy, thereby reaching the maximum capacitance of $595 \mathrm{~F} \mathrm{~g}^{-1}$. At the interface of the NiO/PPy composite, an internal electric field can be induced, and a synergistic effect can occur between $\mathrm{NiO}$ and $\mathrm{PPy} .{ }^{31}$ In particular, the NiO/PPy composite, as a novel electrode material, offers many advantages, such as enlarged contact surface area between the electrode and electrolyte, a short path for ion diffusion, and rich accessible redox reaction sites. Therefore, preparing materials with a stable structure and excellent performance remains a challenge. Our research group prepared tremella-like $\mathrm{NiO}$ by using $\mathrm{Ni}_{3}\left(\mathrm{NO}_{3}\right)_{2}(-$ $\mathrm{OH})_{4}$ as a precursor with a capacitance of $3242 \mathrm{~F} \mathrm{~g}^{-1}$ at $3 \mathrm{~A} \mathrm{~g}^{-1} .^{32}$ The aim was for the NiO/PPy composite to have the capability to improve supercapacitor performance.

On the basis of the above ideas, we synthesized tremella-like $\mathrm{NiO} /$ fish-scale-like PPy by the solvothermal method coupled with in situ polymerization. On the one hand, the tremella-like NiO offers high capacitance. On the other hand, the fish-scale-like PPy not only provides an effective path for electron transport, but also induces additional pseudocapacitance. Owing to the synergistic effect between $\mathrm{NiO}$ and PPy, NiO/PPy-6, as the electrode material of the three-electrode system, can achieve a specific capacitance of $3648.6 \mathrm{~F} \mathrm{~g}^{-1}$ at a current density of $3 \mathrm{~A} \mathrm{~g}^{-1}$. In addition, an asymmetric supercapacitor (ASC) was prepared using NiO/PPy-6 and activated carbon (AC) as the positive electrode and the negative electrode, respectively. NiO/PPy-6//AC exhibits high specific capacitance and good cycle stability (i.e., the specific capacitance of $\mathrm{NiO} / \mathrm{PPy}-6 / / \mathrm{AC}$ remains at $88.2 \%$ after 10000 cycles), and the energy density can reach $333.3 \mathrm{~W} \mathrm{~h} \mathrm{~kg}^{-1}$ at a power density of $2399.99 \mathrm{~W} \mathrm{~kg}^{-1}$. These results signify that NiO/PPy-6 is a competitive electrode in supercapacitor applications.

\section{Experimental}

\subsection{Materials}

Nickel nitrate hexahydrate $\left(\mathrm{Ni}\left(\mathrm{NO}_{3}\right)_{2} \cdot 6 \mathrm{H}_{2} \mathrm{O}\right)$ was purchased from Sigma-Aldrich. Carbamide $\left(\mathrm{CO}\left(\mathrm{NH}_{2}\right)_{2}\right)$, ammonium persulfate (APS), $p$-toluenesulfonamide ( $p$-TSA), pyrrole (py), and ethanol are of analytical grade and were purchased from Tianjin Kemiou Chemical Reagent Co. Ltd. (China). AC was bought from Fuzhou Yihuan Carbon Co. Ltd. (China). All chemicals were used without further purification. Ultrapure water (18.2 $\mathrm{M} \Omega \mathrm{cm}$ ) was used in all of the experiments.

\subsection{Preparation of the NiO microspheres}

NiO with a tremella-like morphology was synthesized successfully in this study. ${ }^{32}$ The NiO precursor was synthesized by the solvothermal method. Briefly, $1.70 \mathrm{~g}$ of $\mathrm{Ni}\left(\mathrm{NO}_{3}\right)_{2} \cdot 6 \mathrm{H}_{2} \mathrm{O}$ and $0.18 \mathrm{~g}$ of $\mathrm{CO}\left(\mathrm{NH}_{2}\right)_{2}$ were dissolved in a mixture of $10 \mathrm{~mL}$ ultrapure water and $50 \mathrm{~mL}$ ethanol and kept under magnetic stirring to obtain a homogeneous solution. The obtained homogeneous solution was subsequently transferred into an autoclave reactor, which was heated in an oven at $180^{\circ} \mathrm{C}$ for $12 \mathrm{~h}$ and then cooled naturally to room temperature. The product was washed several times with water and ethanol and then dried at $60{ }^{\circ} \mathrm{C}$. The product was calcined at $350{ }^{\circ} \mathrm{C}$ for $2 \mathrm{~h}$ to obtain the final product.

\subsection{Preparation of NiO/PPy}

The as-prepared tremella-like NiO was encapsulated by PPy by in situ polymerization in water and alcohol mixture at $0{ }^{\circ} \mathrm{C}$. The obtained tremella-like $\mathrm{NiO}(0.3 \mathrm{~g})$ was dispersed into an aqueous solution of $p$-TSA (1.83 g, $60 \mathrm{~mL}$ of anhydrous alcohol) and sonicated for $30 \mathrm{~min}$. Subsequently, Py monomer was added to the suspension and then stirred for $1 \mathrm{~h}$. An aqueous solution of APS (40 mL, 1 : 1 molar ratio to Py) was added, and the mixture was shielded from light for $24 \mathrm{~h}$. A series of NiO/PPy samples with different molar ratios of Py and $\mathrm{NiO}$ (abbreviated as NiO/PPy- $n$, where " $n$ " is the molar ratio of NiO to Py, which is $2,4,6,8$, and 10 in this study) were synthesized to compare the performances of $\mathrm{NiO} / \mathrm{PPy}$ samples with different thicknesses. The black samples were washed and dried at $60{ }^{\circ} \mathrm{C}$ in air.

\subsection{Characterization}

The external structure of the samples was characterized by field emission scanning electron microscopy (FESEM; Hitachi S4800) equipped with energy dispersive X-ray spectroscopy (EDS). Transmission electron microscopy (TEM) and highresolution TEM (HRTEM) measurements were performed using a JEM-2100 electron microscope. The crystal structure of the products was characterized by X-ray diffraction (XRD, Bruker D8 Advance diffractometer) within the $2 \theta$ range from $10^{\circ}$ to $80^{\circ}$, with $\mathrm{Cu} \mathrm{K} \alpha$ radiation at a wavelength of $0.15406 \mathrm{~nm}$. Fourier transform infrared spectroscopy (FT-IR) was collected on a Bruker Tensor 27 spectrometer in the range of 4000$400 \mathrm{~cm}^{-1}$ using $\mathrm{KBr}$ pellets. X-ray photoelectron spectroscopy (XPS) measurements were performed using ESCALAB 250 with an $\mathrm{Al} \mathrm{K} \alpha \mathrm{X}$-ray source. The specific surface areas and pore size distribution of samples were measured using an $\mathrm{N}_{2}$ adsorptiondesorption apparatus (Micromeritics, TriStar 3020). The specific surface areas were calculated by Brunauer-Emmett-Teller (BET) method, and pore diameters were estimated on the basis of the Barrett-Joyner-Halenda (BJH) model.

\subsection{Electrochemical measurements}

The performances of the supercapacitors were tested by threeelectrode and two-electrode cells with the PARSTAT 4000 electrochemical workstation. The three-electrode cell used a platinum sheet as the counter electrode, a saturated calomel electrode as the reference electrode, the as-prepared electrode as the working electrode, and $6 \mathrm{~mol} \mathrm{~L}^{-1}$ of $\mathrm{KOH}$ solution as the electrolyte. The two-electrode cell was assembled with the same working electrode material used in the three-electrode cell as 
the anode and AC as the cathode. The working electrodes were prepared as follows. The synthesized samples, acetylene black, and polyvinylidene fluoride (PVDF) were mixed in a mass ratio of $80: 10: 10$ in $N$-methyl-2-pyrrolidinone to form a homogeneous slurry. The slurry was coated with nickel foam as the current collector, and the electrode area was $1 \mathrm{~cm}^{2}$. The electrode was dried at $80{ }^{\circ} \mathrm{C}$ under vacuum for $12 \mathrm{~h}$. The electrochemical performances were analyzed by cyclic voltammetry (CV), galvanostatic charge-discharge (GCD), and electrochemical impedance spectroscopy (EIS). For the three-electrode cell, CV curves were measured at potentials of 0-0.4 V, and GCD tests were conducted at potentials of $0-0.37 \mathrm{~V}$. For the twoelectrode cell, CV curves were measured at potentials of 0 1.6 V, and GCD tests were conducted at potentials of 0-1.6 V.

Specific capacitance, which was determined from the charge-discharge curve, was calculated as follows [eqn (1)]:

$$
C_{\mathrm{s}}=\frac{I \Delta t}{m \Delta V}
$$

where $C_{\mathrm{s}}$ refers to specific capacitance $\left(\mathrm{F} \mathrm{g}^{-1}\right), I$ represents the discharge current (A), $\Delta t$ denotes the discharge time (s), $\Delta V$ stands for the potential window $(\mathrm{V})$, and $m$ corresponds to the mass of active materials on the working electrode $(\mathrm{g})$.

The energy density $(E)$ and the power density $(P)$ of the assembled supercapacitor were calculated on the basis of the charge-discharge curves as follows [eqn (2) and (3)]:

$$
\begin{gathered}
E=\frac{C_{\mathrm{s}} \Delta V^{2}}{7.2} \\
P=\frac{3600 E}{t}
\end{gathered}
$$

where $C_{\mathrm{s}}$ is the specific capacitance $\left(\mathrm{F} \mathrm{g}^{-1}\right), \Delta V$ is indicates the potential window $(\mathrm{V})$, and $t$ is the discharge time $(\mathrm{s})$.

\section{Results and discussion}

Fig. $\mathrm{S} 1 \uparrow$ shows the FESEM images of the prepared $\mathrm{Ni}_{3}\left(\mathrm{NO}_{3}\right)_{2}(-$ $\mathrm{OH})_{4}$ precursors. The precursor is completely orbicular with a diameter of $\sim 4 \mu \mathrm{m}$, and the nanosheets are tightly packed with a thickness of $\sim 10 \mathrm{~nm}$. The morphologies of $\mathrm{NiO}$ and $\mathrm{NiO} /$ PPy are characterized by FESEM, as shown in Fig. 1. As shown in Fig. 1a and d, the low-magnification findings are uniform for the NiO and NiO/PPy- 6 microspheres. The diameter $(\sim 4 \mu \mathrm{m})$ of the tremella-like NiO microsphere is composed of nanosheets with a thickness of $\sim 10 \mathrm{~nm}$ (Fig. 1a and b). The nanosheets can provide additional space for Py polymerization and shorten the length of ion diffusion in the electrolyte. Fig. 1c and d show the $\mathrm{NiO} / \mathrm{PPy}$ microsphere with a compact structure, and the nanosheets are thick at $\sim 30 \mathrm{~nm}$.

The microstructures of $\mathrm{NiO}$ and $\mathrm{NiO} / \mathrm{PPy}$ are further analyzed by TEM and HRTEM (Fig. 2). The TEM images of the $\mathrm{NiO}$ and NiO/PPy microspheres are shown in Fig. 2a and b. The $\mathrm{NiO}$ microsphere is uniformly embedded with PPy in the NiO gaps (Fig. 2c). Fig. 2d shows that the PPy is fish-scale-like, with a thickness of $\sim 10 \mathrm{~nm}$ and connected to the surface of an NiO nanosheet. The morphology and size of the NiO and NiO/PPy
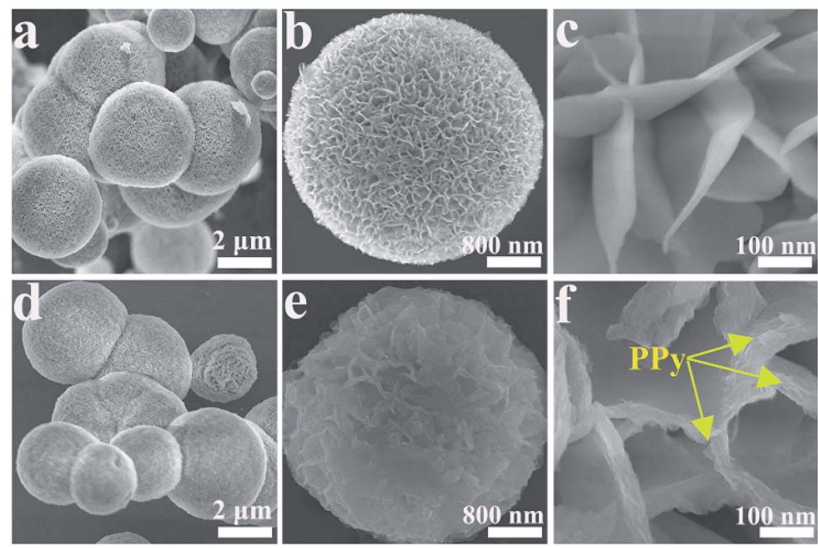

Fig. 1 FESEM images of $\mathrm{NiO}(\mathrm{a}-\mathrm{c})$ and $\mathrm{NiO} / \mathrm{PPy}(\mathrm{d}-\mathrm{f})$.

microspheres conform with the FESEM results. In addition, PPy has a fish-scale-like morphology, which can provide additional active sites for $\mathrm{OH}^{-}$insertion. ${ }^{33-35}$ Energy-dispersive X-ray (EDX) spectroscopy (Fig. 2e) reveals that $\mathrm{Ni}, \mathrm{O}, \mathrm{C}$, and $\mathrm{N}$ elements exist in the NiO/PPy microspheres. The mapping
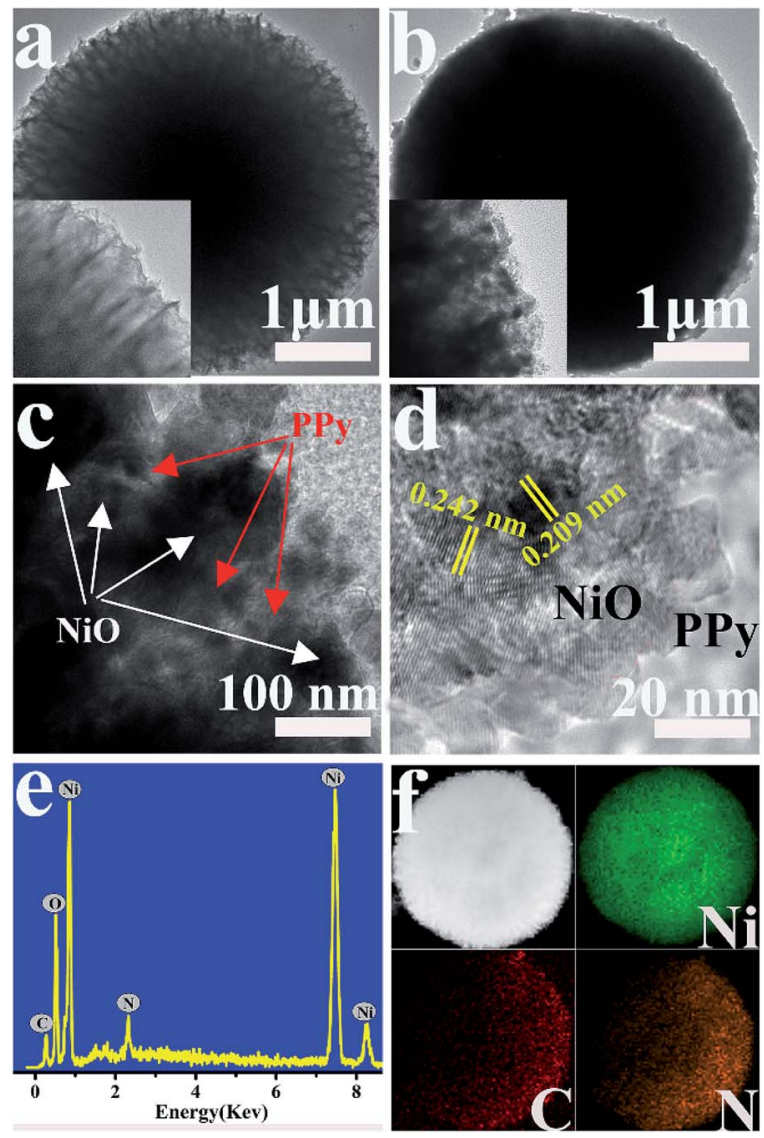

Fig. 2 TEM images of $\mathrm{NiO}$ (a). TEM and HRTEM images of NiO/PPy (bd). Insets in (a) and (b) are the edge magnification TEM images, respectively. The dashed line in (c) and (d) shows the contact surface between $\mathrm{NiO}$ and PPy. (e) EDX spectrum for NiO/PPy. (f) FESEM image and corresponding EDX elemental mapping images of $\mathrm{Ni}, \mathrm{C}$, and $\mathrm{N}$ for $\mathrm{NiO} / \mathrm{PPy}$. 


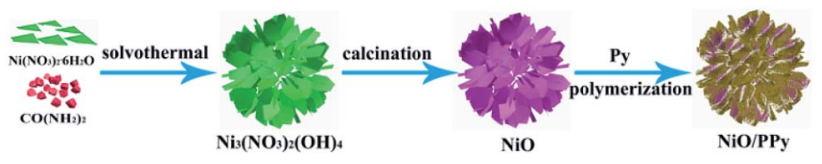

Scheme 1 The mechanism for synthesis processes of NiO/PPy.

images (Fig. 2f) confirm the distribution of the constituents of $\mathrm{NiO} / \mathrm{PPy}$ with $\mathrm{Ni}, \mathrm{N}$, and $\mathrm{C}$ elements.

The synthesis mechanism of the NiO/PPy microspheres is depicted in Scheme 1. First, $\mathrm{Ni}\left(\mathrm{NO}_{3}\right)_{2} \cdot 6 \mathrm{H}_{2} \mathrm{O}$ slowly undergoes alcoholysis in ethanol and $\mathrm{CO}\left(\mathrm{NH}_{2}\right)_{2}$ to form tremella-like $\mathrm{Ni}_{3}\left(\mathrm{NO}_{3}\right)_{2}(\mathrm{OH})_{4}$ microspheres. ${ }^{32}$ Tremella-like NiO microspheres can be obtained after calcination. Then, the PPy layers are grown on the surfaces of the NiO nanosheets by the chemical oxidation polymerization of Py ${ }^{36,37}$ Wrinkly PPy films with fish-scale-like morphologies on the surfaces of the NiO nanosheets are fabricated.

Compared with the XRD spectrum of pure NiO, the XRD spectrum of NiO/PPy is not affected during Py polymerization (Fig. 3a). All diffraction peaks of $\mathrm{NiO} / \mathrm{PPy}$ are the same as those of NiO (JCPDS: 65-5745). This finding suggests the lack of influence on the crystal structure of NiO after Py polymerization, and the fish-scale-like PPy is an amorphous structure. The XRD patterns of the pristine precursors were subsequently
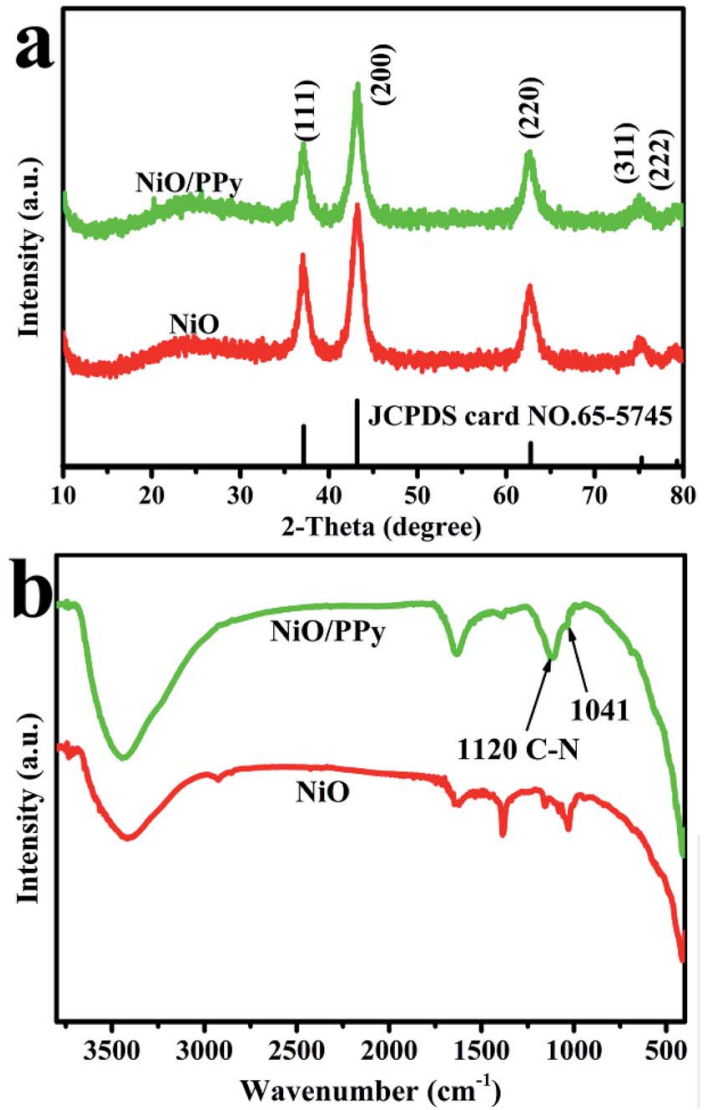

Fig. 3 XRD patterns of $\mathrm{NiO}$ and $\mathrm{NiO} / \mathrm{PPy}$ (a). FT-IR spectra of $\mathrm{NiO}$ and $\mathrm{NiO} / \mathrm{PPy}(\mathrm{b})$. compared, as shown in Fig. S2. $\dagger$ All diffraction peaks located at $13.1^{\circ}, 26.0^{\circ}, 34.2^{\circ}, 35.9^{\circ}, 43.8^{\circ}, 53.9^{\circ}, 59.8^{\circ}$, and $61.0^{\circ}$ can be indexed to the (001), (002), (100), (101), (102), (103), (110), and (111) hexagonal structures of $\mathrm{Ni}_{3}\left(\mathrm{NO}_{3}\right)_{2}(\mathrm{OH})_{4}$ (JCPDS card no. 22-0752). The FT-IR spectra of the NiO and NiO/PPy microspheres are also obtained to further investigate the $\mathrm{NiO} / \mathrm{PPy}$, as shown in Fig. 3b. In the FT-IR spectrum of NiO/PPy, two new peaks located at $1120 \mathrm{~cm}^{-1}$ (associated with the $\mathrm{C}-\mathrm{N}$ bond) and $1041 \mathrm{~cm}^{-1}$ (associated with the Py ring), which are characteristic absorption peaks, are observed after in situ polymerization.

Fig. S3† shows that all samples exhibit typical type-IV isotherms with clear hysteresis loops of $\mathrm{H} 3$ type, which indicate typical mesoporous structures. As shown in Fig. S3b, $\uparrow$ the pore sizes of $\mathrm{NiO}$ and $\mathrm{NiO} / \mathrm{PPy}$ are mainly in the mesoporous range $(\sim 5 \mathrm{~nm})$. The specific surface areas of $\mathrm{NiO}$ and $\mathrm{NiO} / \mathrm{PPy}$ are 150 and $248 \mathrm{~m}^{2} \mathrm{~g}^{-1}$, and the pore volumes of $\mathrm{NiO}$ and $\mathrm{NiO} / \mathrm{PPy}$ are 3.906 and $6.209 \mathrm{~m}^{3} \mathrm{~g}^{-1}$, respectively. That is, $\mathrm{NiO} /$ PPy possesses a larger surface area and pore volume than NiO.

The XPS spectrum of NiO/PPy shows that $\mathrm{Ni}, \mathrm{O}, \mathrm{C}$, and $\mathrm{N}$ coexist in the composite (Fig. 4a). Fig. $4 \mathrm{~b}$ shows that the two peaks detected at 854.0 and $872.6 \mathrm{eV}$ for the $\mathrm{Ni} 2 \mathrm{p}$ spectra of $\mathrm{NiO} / \mathrm{PPy}$, are assigned to $\mathrm{Ni} 2 \mathrm{p}_{3 / 2}$ and $\mathrm{Ni} 2 \mathrm{p}_{1 / 2}$, can be ascribed to $\mathrm{Ni}^{2+} \cdot{ }^{38}$ The $\mathrm{C} 1 \mathrm{~s}$ spectrum of XPS is fitted into three components (Fig. 4c). The peaks at 284.1, 286.0, and $287.5 \mathrm{eV}$ correspond to $\mathrm{C}_{\beta}$ and $\mathrm{C}_{\alpha}$ PPy $(\mathrm{C}-\mathrm{C}), \mathrm{C}-\mathrm{OH}$ or $\mathrm{C}=\mathrm{N}$, and $\mathrm{C}=\mathrm{O}$, respectively. ${ }^{39}$ In the $\mathrm{N}$ 1s XPS spectra (Fig. 4d), the peak at $397.8 \mathrm{eV}$ can be attributed to the imine-like $(=\mathrm{N}-)$ morphology, the peak at $399.2 \mathrm{eV}$ corresponds to Py nitrogen $(-\mathrm{NH}-)$, and the peak at $401.1 \mathrm{eV}$ can be assigned to positively charged nitrogen $\left(-\mathrm{NH}^{+}-\right) .^{15}$

Fig. 5a shows the CV curves of $\mathrm{NiO}$ and $\mathrm{NiO} / \mathrm{PPy}-n$ tested at a scan rate of $10 \mathrm{mV} \mathrm{s}^{-1}$ in the three-electrode system. The $\mathrm{CV}$ curves of $\mathrm{NiO}$ and $\mathrm{NiO} / \mathrm{PPy}-n$ present two pairs of redox peaks. With the increase in molar ratio of $\mathrm{NiO}$ to Py, the area of the $\mathrm{CV}$ curve is increased until the molar ratio of $\mathrm{NiO}$ to $\mathrm{Py}$ is 6 . At the same scan rate, $\mathrm{NiO} / \mathrm{PPy}-6$ has the highest specific capacitance. When the amount of PPy increases, the excess in PPy hinders the $\mathrm{OH}^{-}$ion from entering the NiO. ${ }^{15,29,40}$ The mechanism is
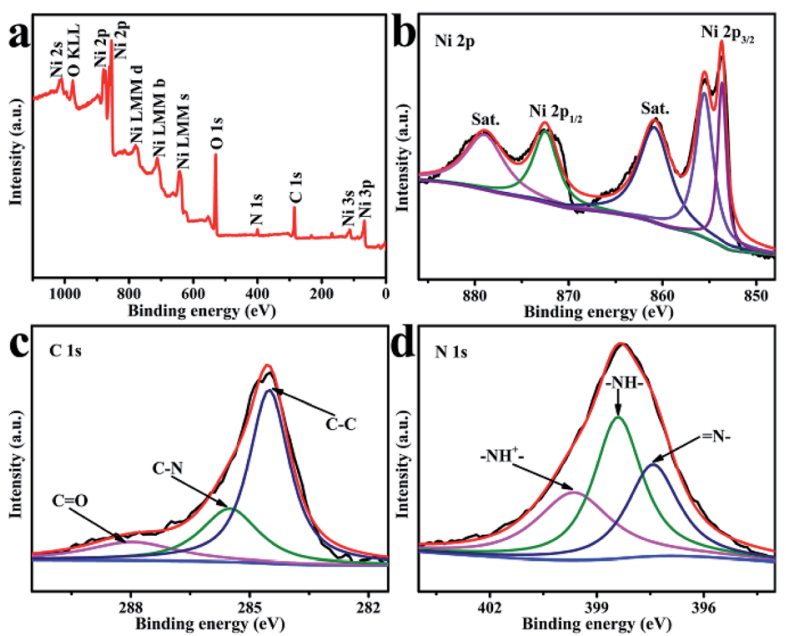

Fig. 4 XPS survey spectrum for NiO/PPy (a). High-resolution XPS spectra (b) Ni 2p, (c) C 1s, and (d) N 1s. 

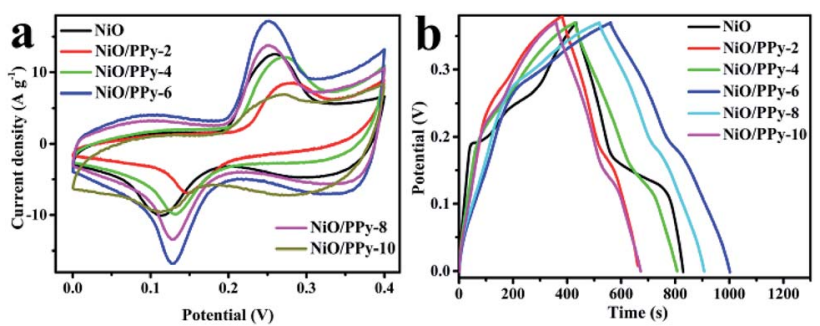

Fig. 5 Comparison of $\mathrm{CV}$ curves of $\mathrm{NiO}$ and $\mathrm{NiO} / \mathrm{PPy}$ at a scan rate of $10 \mathrm{mV} \mathrm{s}^{-1}$ (a). Comparison of GCD curves of $\mathrm{NiO}$ and NiO/PPy at a current density of $3 \mathrm{~A} \mathrm{~g}^{-1}$ (b)

attributed to the reversible faradaic redox of $\mathrm{Ni}^{2+} / \mathrm{Ni}^{3+}$, according to the following equation: $:^{32,41}$

$$
\mathrm{NiO}+\mathrm{OH}^{-} \leftrightarrow \mathrm{NiOOH}+\mathrm{e}^{-}
$$

Fig. $5 \mathrm{~b}$ shows the GCD curves of $\mathrm{NiO}$ and $\mathrm{NiO} / \mathrm{PPy}-n$ tested at a current density of $3 \mathrm{~A} \mathrm{~g}^{-1}$. The NiO/PPy- 6 electrode has the longest discharge time among all samples. The results indicate that $\mathrm{NiO} / \mathrm{PPy}-6$ is the optimal electrode in the supercapacitors.

The CV curves of NiO and NiO/PPy- 6 at different scan rates are shown in Fig. 6a and c. When the scan rate increases, the polarization effect of the electrode is enhanced, and oxidation peaks and reduction peaks move to a high potential and a low potential, respectively. ${ }^{1}$ The $\mathrm{CV}$ curves of $\mathrm{NiO} / \mathrm{PPy}-6$ appear with a symmetrical shape (Fig. 6c), suggesting an increase in coulombic efficiency and a decrease in polarization loss. ${ }^{1,42}$ The GCD curves of NiO and NiO/PPy-6 have good symmetry (Fig. 6b and d), indicating superior reversible redox capabilities. Fig. S4a $\dagger$ shows the specific capacitance of $\mathrm{NiO}$ and NiO/PPy-6 at various current densities. When the current density increases from $3 \mathrm{~A} \mathrm{~g}^{-1}$ to $30 \mathrm{~A} \mathrm{~g}^{-1}$, the capacitance of the $\mathrm{NiO} /$ PPy-6 electrode decreases from $3648.6 \mathrm{~F} \mathrm{~g}^{-1}$ to $1783 \mathrm{~F} \mathrm{~g}^{-1}$. The capacitance of the NiO electrode decreases from $3242 \mathrm{~F} \mathrm{~g}^{-1}$ to
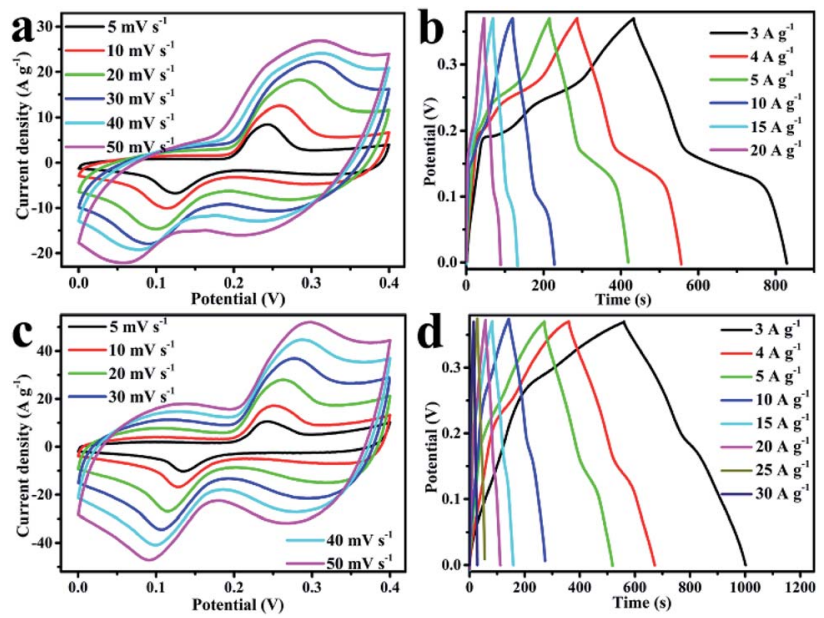

Fig. $6 \mathrm{CV}$ curves of (a) $\mathrm{NiO}$ and (c) NiO/PPy- 6 at different scan rates from 5 to $50 \mathrm{mV} \mathrm{s}^{-1}$. GCD curves of (b) $\mathrm{NiO}$ at different current densities from $3 \mathrm{~A} \mathrm{~g}^{-1}$ to $20 \mathrm{~A} \mathrm{~g}^{-1}$ and (d) NiO/PPy- 6 at different current densities from $3 \mathrm{~A} \mathrm{~g}^{-1}$ to $30 \mathrm{~A} \mathrm{~g}^{-1}$.
$81 \mathrm{~F} \mathrm{~g}^{-1}$ when the current density increases from $3 \mathrm{~A} \mathrm{~g}^{-1}$ to $20 \mathrm{~A} \mathrm{~g}^{-1}$. Nevertheless, at each current density, the specific capacitance of $\mathrm{NiO} / \mathrm{PPy}$ is larger than that of NiO. A comparison of NiO/PPy-6 and NiO composite electrodes is provided in Table S1. $\dagger$

EIS measurement was carried out in the frequency range from $100 \mathrm{kHz}$ to $0.01 \mathrm{~Hz}$. Fig. S4b† shows the Nyquist plots of $\mathrm{NiO}$ and NiO/PPy-6. In the high-frequency region, the semicircular diameter of NiO/PPy-6 is smaller than that of NiO, which indicates that the introduction of PPy can increase $\mathrm{OH}^{-}$ ion transport. ${ }^{43,44}$ In the low-frequency region, the line slope of $\mathrm{NiO} / \mathrm{PPy}-6$ is larger than that of NiO, which demonstrates that the diffusion resistance of $\mathrm{NiO} / \mathrm{PPy}-6$ is lower than that of NiO. ${ }^{45,46}$ Therefore, NiO/PPy-6 has superior capacitance properties.

In further evaluating the advantages of NiO/PPy- 6 composites in practical applications, NiO/PPy-6//AC ASC is fabricated using NiO/PPy- 6 and AC as the positive electrode and negative electrode, respectively. The negative electrode is prepared by the traditional slurry coating method. AC, acetylene black, and PVDF are mixed in a mass ratio of $80: 10: 10$. PVDF is dissolved in $N$-methylpyrrolidone, then the sample and acetylene black are dispersed in the above solution. The mixtures are ground adequately to form a slurry. Subsequently, the slurry is pasted onto the treated $\mathrm{Ni}$ foam and dried at $85{ }^{\circ} \mathrm{C}$ for $24 \mathrm{~h}$. Fig. 7a presents a schematic illustration of ASC, while Fig. S5† shows the $\mathrm{CV}$ and GCD curves of AC. The capacitance of NiO, NiO/PPy6 , and $\mathrm{AC}$ at $3 \mathrm{~A} \mathrm{~g}^{-1}$ are $656.2 \mathrm{~F} \mathrm{~g}^{-1}, 937.5 \mathrm{~F} \mathrm{~g}^{-1}$, and $480 \mathrm{~F} \mathrm{~g}^{-1}$, respectively.

$\mathrm{CV}$ curves of NiO/PPy- 6 and $\mathrm{AC}$ are measured at $30 \mathrm{mV} \mathrm{s}^{-1}$ in a three-electrode system to determine the total voltage, as shown in Fig. 7b. The voltage window of the ASC device is predicted to reach $1.6 \mathrm{~V}$. Fig. $7 \mathrm{c}$ and $\mathrm{d}$ show the CV and GCD curves of ASC. The results also show that the voltage of ASC can reach 1.6 V. NiO/PPy-6//AC has a large CV area and high capacitance compared with NiO//AC (Fig. 7e). Fig. 7f presents the discharge time of NiO/PPy-6//AC (500 s), which is longer than that of $\mathrm{NiO} / / \mathrm{AC}(349.9 \mathrm{~s})$ at $3 \mathrm{~A} \mathrm{~g}^{-1}$.

$\mathrm{CV}$ curves of $\mathrm{NiO} / \mathrm{PPy}-6 / / \mathrm{AC}$ and $\mathrm{NiO} / / \mathrm{AC}$ in the voltage window of $0-1.6 \mathrm{~V}$ at different scan rates are shown in Fig. 8a and S6a. $\dagger$ When the scan rate increases, the CV curve is maintained, suggesting a satisfactory rate and good cycling performance of ASC. ${ }^{47,48}$ The GCD curves of NiO/PPy-6//AC and NiO// $\mathrm{AC}$ at the different current densities of $3-20 \mathrm{~A} \mathrm{~g}^{-1}$ in the voltage window of $0-1.6 \mathrm{~V}$ are shown in Fig. $8 \mathrm{~b}$ and S6b. $\dagger$ As shown in Fig. 8c, at the current densities of $3 \mathrm{~A} \mathrm{~g}^{-1}$ and $20 \mathrm{~A} \mathrm{~g}^{-1}$, the NiO/PPy-6//AC has a high specific capacitance of $937.5 \mathrm{~F} \mathrm{~g}^{-1}$ and $625 \mathrm{~F} \mathrm{~g}^{-1}$, which are higher than those of the $\mathrm{NiO} / / \mathrm{AC}$ (656.2 $\mathrm{F} \mathrm{g}^{-1}$ and $400 \mathrm{~F} \mathrm{~g}^{-1}$ ). The cycle stability, an important parameter for supercapacitors, of $\mathrm{NiO} / \mathrm{PPy}-6 / / \mathrm{AC}$ can be valued by its consecutive GCD at $10 \mathrm{~A} \mathrm{~g}^{-1}$ for 10000 cycles. As shown in Fig. 8d, the capacitance retention is over $100 \%$ for 1200 cycles and then gradually decreases. ${ }^{20,49}$ After 10000 cycles, the specific capacitance of $\mathrm{NiO} / \mathrm{PPy}-6 / / \mathrm{AC}$ remains at $88.2 \%$ of the initial value, indicating excellent long-term cycling stability. Power and energy densities, as the two significant parameters of supercapacitors, are obtained based on ASC to identify the 

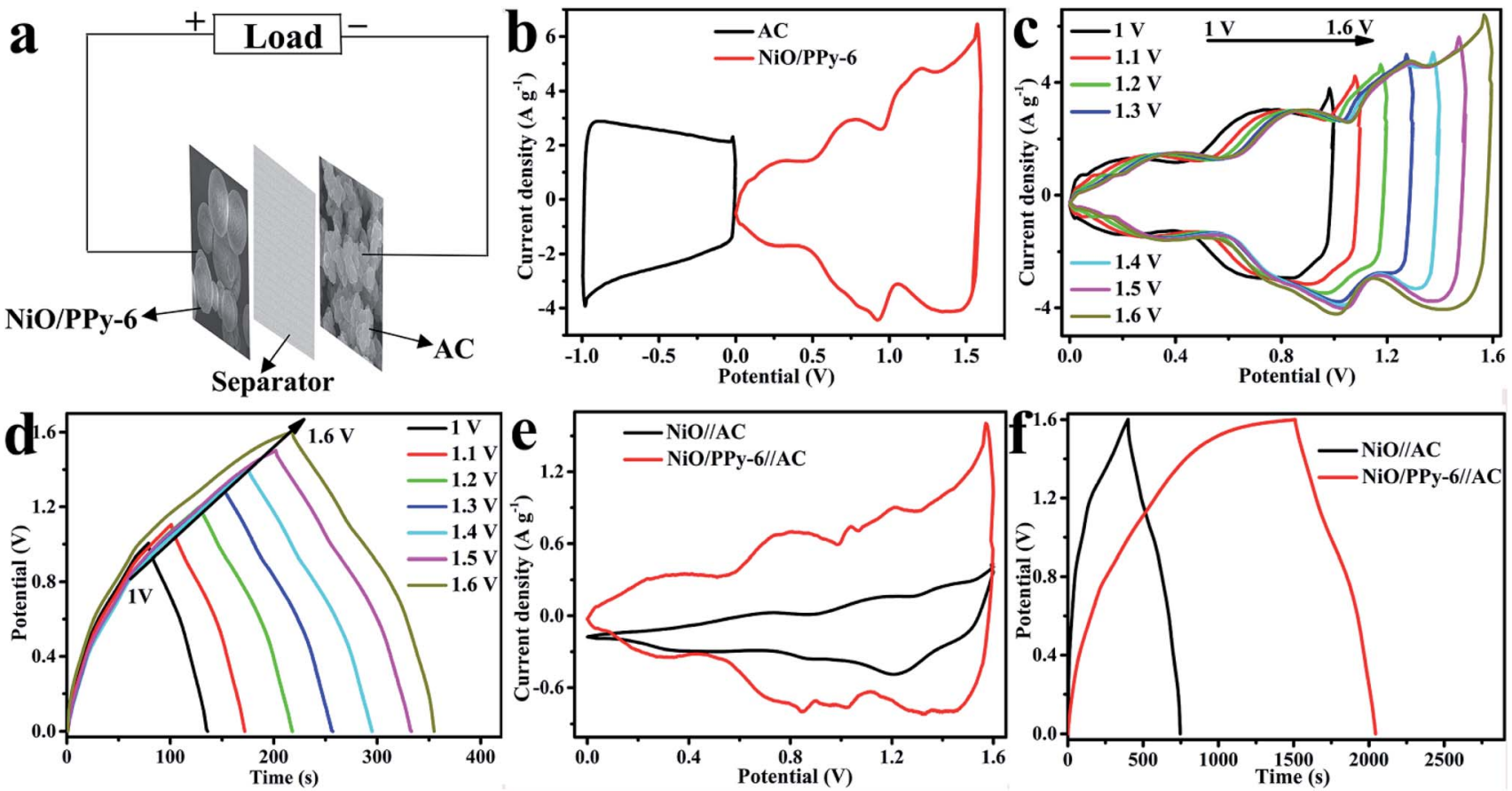

Fig. 7 (a) Schematic illustration of the assembled asymmetric supercapacitor configuration; (b) CV curves of NiO/PPy-6 and AC electrodes at a scan rate of $30 \mathrm{mV} \mathrm{s}^{-1}$; (c) CV curves of $\mathrm{NiO} / \mathrm{PPy}-6 / / \mathrm{AC}$ asymmetric supercapacitor collected in different voltage windows at a scan rate of $30 \mathrm{mV} \mathrm{s}^{-1}$; (d) GCD curves of NiO/PPy-6//AC asymmetric supercapacitor collected in different voltage windows at a current density of $10 \mathrm{~A} \mathrm{~g}^{-1}$; (e) $\mathrm{CV}$ curves of $\mathrm{NiO} / \mathrm{PPy}-6 / / \mathrm{AC}$ and $\mathrm{NiO} / / \mathrm{AC}$ at a scan rate of $5 \mathrm{mV} \mathrm{s}^{-1}$; (f) GCD curves of NiO/PbPy-6//AC and NiO//AC at a current density of $3 \mathrm{~A} \mathrm{~g}^{-1}$.

applicability of the special materials. Fig. 8e shows a comparison of the Ragone plots of $\mathrm{NiO} / / \mathrm{AC}$ and NiO/PPy-6//AC. At the current densities of $3 \mathrm{~A} \mathrm{~g}^{-1}$ and $20 \mathrm{~A} \mathrm{~g}^{-1}$, NiO/PPy-6//AC has energy densities of $333.3 \mathrm{~W} \mathrm{~h} \mathrm{~kg}^{-1}$ and $222.22 \mathrm{~W} \mathrm{~h} \mathrm{~kg}^{-1}$ at power densities of $2399.8 \mathrm{~W} \mathrm{~kg}^{-1}$ and $15999 \mathrm{~W} \mathrm{~kg}^{-1}$, respectively. These values are higher than those of NiO//AC. For
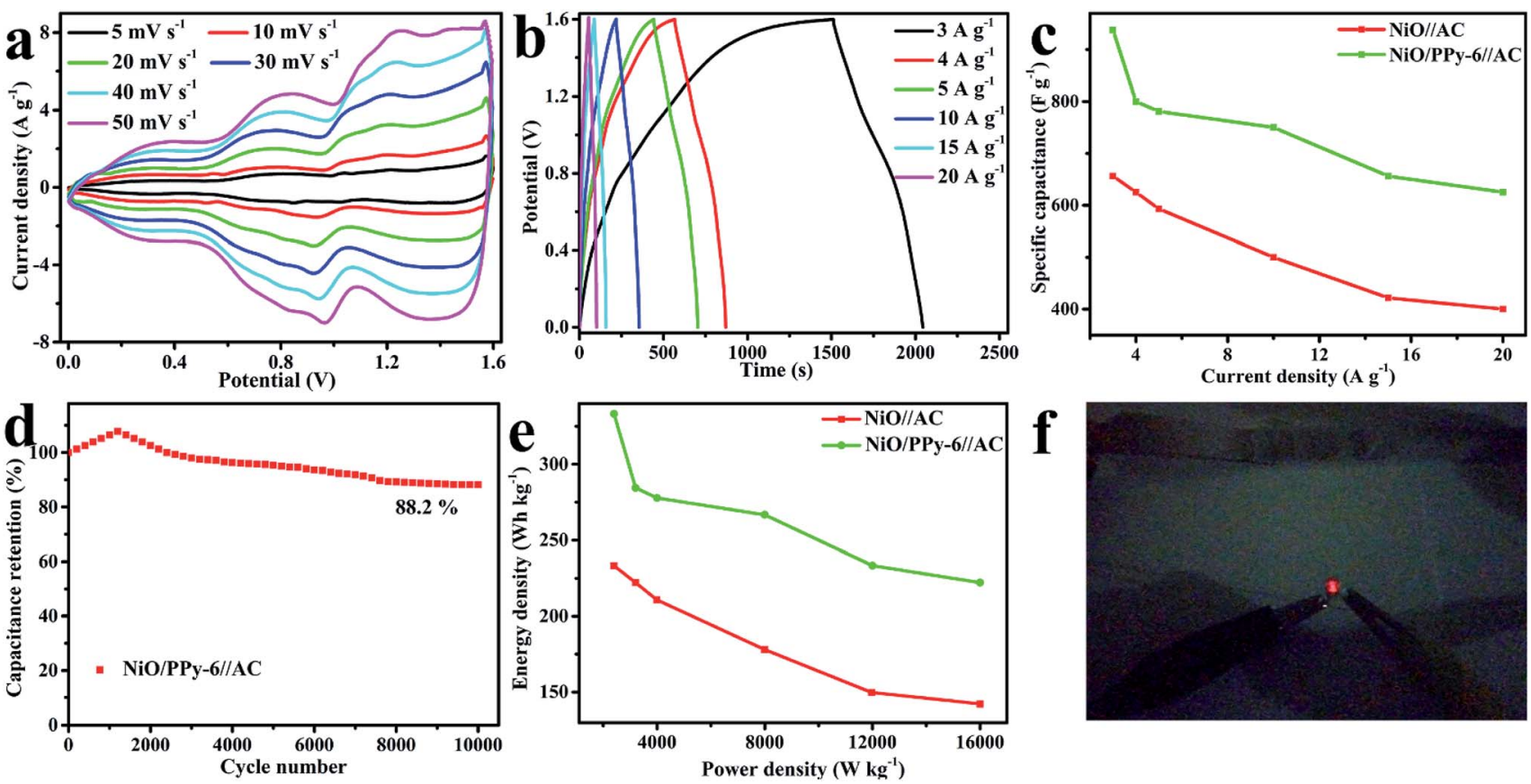

Fig. 8 (a) CV curves of NiO/PPy-6//AC at different scan rates; (b) GCD curves of NiO/PPy-6//AC at different current densities; (c) specific capacitances of $\mathrm{NiO} / / \mathrm{AC}$ and $\mathrm{NiO} / \mathrm{PPy}-6 / / \mathrm{AC}$ at different current densities; (d) cycling performance of NiO/PPy-6//AC at a current density of $10 \mathrm{~A} \mathrm{~g}^{-1}$; (e) Ragone plots of energy density and power density of NiO/PPy//AC and NiO//AC; (f) a image of LED lighted up by NiO/PPy//AC ASC. 
further application of ASC in actual life, the above configuration can easily light LED indicators (Fig. 8f).

\section{Conclusions}

Tremella-like NiO/fish-scale-like PPy microspheres were fabricated by solvothermal and in situ polymerization methods. The nanosheets of tremella-like NiO limit the Py chemical oxidation polymerization, which can subsequently shorten the distance of $\mathrm{OH}^{-}$ion diffusion. The fish-scale-like PPy can provide many active sites. As an electrode material in supercapacitors, the combination of $\mathrm{NiO} / \mathrm{PPy}$ produces an advantageous synergistic effect. The optimized NiO/PPy- 6 achieved a high specific capacitance of $3648.6 \mathrm{~F} \mathrm{~g}^{-1}$ at $3 \mathrm{~A} \mathrm{~g}^{-1}$. NiO/PPy-6//AC ASC was assembled using $\mathrm{NiO} / \mathrm{PPy}-6$ and $\mathrm{AC}$ as the positive electrode and the negative electrode, respectively. The ASC device can achieve high specific capacitance of $937.5 \mathrm{~F} \mathrm{~g}^{-1}$ at $3 \mathrm{~A} \mathrm{~g}^{-1}$ and an energy density of $333.3 \mathrm{~W} \mathrm{~h} \mathrm{~kg}^{-1}$ at a power density of $2399.99 \mathrm{~W} \mathrm{~kg}^{-1}$. The specific capacitance of $\mathrm{NiO} / \mathrm{PPy}-6 / / \mathrm{AC}$ remains at $88.2 \%$ after 10000 cycles, indicating excellent long-term cycling stability. Consequently, NiO/PPy-6//AC is a competitive candidate for energy conversion and reserve devices.

\section{Conflicts of interest}

There are no conflicts to declare.

\section{Acknowledgements}

This work was supported by the National Natural Science Foundation of China (Grant No. 51572134, 51372124) and the Program for Scientific Research Innovation Team in Colleges and Universities of Jinan (Grant No. 2018GXRC006).

\section{Notes and references}

1 H. W. Lai, Q. Wu, J. Zhao, L. M. Shang, H. Li, R. C. Che, Z. Y. Lyu, J. F. Xiong, L. J. Yang, X. Z. Wang and Z. Hu, Energy Environ. Sci., 2016, 9, 2053-2060.

2 B. Dunn, H. Kamath and J. M. Tarascon, Science, 2011, 334, 928-935.

3 Y. Shi, J. Zhang, A. M. Bruck, Y. M. Zhang, J. Li, E. A. Stach, K. J. Takeuchi, A. C. Marschilok, E. S. Takeuchi and G. H. Yu, Adv. Mater., 2017, 29, 1603922-1603929.

4 A. Gupta, P. Singh, C. Mullins, M. Buddie and J. B. Goodenough, Chem. Mater., 2016, 28, 4641-4645.

5 K. Naoi, W. Naoi, S. Aoyagi, J. I. Miyamoto and T. Kamino, Acc. Chem. Res., 2012, 46, 1075-1083.

6 R. R. Salunkhe, C. Young, J. Tang, T. Takei, Y. Ide, N. Kobayashi and Y. Yamauchi, Chem. Commun., 2016, 52, 4764-4767.

7 R. R. Salunkhe, Y. V. Kaneti, J. Kim, J. H. Kim and Y. Yamauchi, Acc. Chem. Res., 2016, 49, 2796-2806.

8 S. G. Chen, Z. D. Wei, X. Q. Qi, L. C. Dong, Y. G. Guo, L. J. Wan, Z. G. Shao and L. Li, J. Am. Chem. Soc., 2012, 134, 13252-13255.
9 Q. X. Xia, J. Fu, J. M. Yun, R. S. Maneb and K. H. Kim, RSC Adv., 2017, 7, 11000-11011.

10 S. R. Ede, S. Anantharaj, K. T. Kumaran, S. Mishrab and S. Kundu, RSC Adv., 2017, 7, 5898-5911.

11 Q. H. Gong, Y. J. Li, H. Huang, J. Zhang, T. T. Gao and G. W. Zhou, Chem. Eng. J., 2018, 344, 290-298.

12 X. Wang, T. M. Wang, D. Liu, J. S. Guo and P. Liu, Ind. Eng. Chem. Res., 2016, 55, 866-874.

13 J. H. Yang, X. Xie, Z. Z. He, Y. Lu, X. D. Qi and Y. Wang, Chem. Eng. J., 2019, 355, 137-149.

14 S. Saha, M. Jana, P. Khanra, P. Samanta, H. Koo, N. C. Murmub and T. Kuila, RSC Adv., 2016, 6, 1380-1387.

15 J. F. Sun, Y. Huang, C. X. Fu, Z. Y. Wang, Y. Huang, M. S. Zhu, C. Y. Zhi and H. Hu, Nano Energy, 2016, 27, 230-237.

16 T. Y. Tao, J. F. Ruan, W. M. Zhang, Z. P. Tan, J. H. Yang, Z. F. Ma and S. Y. Zheng, ACS Appl. Mater. Interfaces, 2016, 8, 35114-35122.

17 J. Xu, A. Palumbo, W. Xu and E. H. Yang, J. Phys. Chem. B, 2016, 120, 10381-10386.

18 B. B. Yue, C. Y. Wang, W. Pawel, Y. Yang, X. Ding, D. L. Officer and G. G. Wallace, Synth. Met., 2012, 162, 2216-2221.

19 M. L. Yan, Y. D. Yao, J. Q. Wen, L. Long, M. L. Kong, G. G. Zhang, X. M. Liao, G. F. Yin and Z. B. Huang, ACS Appl. Mater. Interfaces, 2016, 8, 24525-24535.

20 X. R. Sun, H. W. Zhang, L. Zhou, X. D. Huang and C. Z. Yu, Small, 2016, 12, 3732-3737.

21 X. M. Wu, L. Meng, Q. G. Wang, W. Z. Zhang and Y. Wang, Chem. Eng. J., 2017, 327, 193-201.

22 W. Hong, J. Q. Wang, Z. P. Li and S. G. Yang, J. Mater. Chem. A, 2015, 3, 2535-2540.

23 L. J. Han, P. Y. Tang and L. Zhang, Nano Energy, 2014, 7, 4251.

24 P. B. Liu, Y. Huang, L. Wang and W. Zhang, J. Alloys Compd., 2013, 573, 151-156.

25 L. Z. Bai, Z. P. Li, Y. Zhang, T. Wang, R. H. Lu, W. F. Zhou, H. X. Gao and S. B. Zhang, Chem. Eng. J., 2015, 279, 757-766.

26 J. Liu, X. J. Xu, R. Z. Hu, L. C. Yang and M. Zhu, Adv. Energy Mater., 2016, 6, 1600256-1600262.

27 Y. Wang, Y. Zhang, C. Hou and M. Z. Liu, Microchim. Acta, 2016, 183, 1145-1152.

28 J. J. Yuan, C. H. Chen, Y. Hao, X. K. Zhang, B. Zou, R. Agrawal, C. L. Wang, H. J. Yu, X. R. Zhu, Y. Yu, Z. Z. Xiong, Y. Luo, H. X. Li and Y. M. Xie, J. Alloys Compd., 2017, 691, 34-39.

29 Q. F. Wang, Y. Ma, X. Liang, D. H. Zhang and M. G. Miao, J. Mater. Chem. A, 2018, 6, 10361-10369.

30 P. Man, Q. C. Zhang, J. Sun, J. B. Guo, X. N. Wang, Z. Y. Zhou, B. He, Q. L. Li, L. Y. Xie, J. X. Zhao, C. W. Li, Q. G. Li and Y. G. Yao, Carbon, 2018, 139, 21-28.

31 W. J. Ji, J. Y. Ji, X. H. Cui, J. J. Chen, D. J. Liu, H. Deng and Q. Fu, Chem. Commun., 2015, 51, 7669-7672.

32 K. H. Han, H. Huang, Q. H. Gong, T. T. Si, Z. L. Zhang and G. W. Zhou, J. Mater. Sci., 2018, 53, 12477-12491.

33 S. M. Wang, T. T. Gao, Y. Li, S. C. Li and G. W. Zhou, J. Solid State Electrochem., 2016, 21, 705-714. 
34 J. Zhang, Y. J. Li, T. T. Gao, X. F. Sun, P. Cao and G. W. Zhou, Ceram. Int., 2018, 44, 8550-8555.

35 X. Zhang, R. F. Zhao, Q. H. Wu, W. L. Li, C. Shen, L. B. Ni, H. Yan, G. W. Diao and M. Chen, ACS Nano, 2017, 11, 8429-8436.

36 C. F. Yang, L. L Li, J. X. Zhao, J. J. Wang, J. X. Xie, Y. P. Cao, M. Q. Xue and C. H. Lu, ACS Appl. Mater. Interfaces, 2018, 10, 25811-25818.

37 X. Yang, Y. Zhao, J. X. Xie, H. Xue, J. J. Wang, C. Y. Zong, H. P. Ji, J. X. Zhao, S. C. Jiang, Y. P. Cao and C. H. Lu, ACS Nano, 2016, 10, 3801-3808.

38 L. F. Shen, J. Wang, G. Y. Xu, H. S. Li, H. Dou and X. G. Zhang, Adv. Energy Mater., 2015, 5, 1400977-1400983.

39 V. A. Zinovyeva, M. A. Vorotyntsev, I. Bezverkhyy, D. Chaumont and J. C. Hierso, Adv. Funct. Mater., 2011, 21, 1064-1075.

40 C. Zhou, Y. W. Zhang, Y. Y. Li and J. P. Liu, Nano Lett., 2013, 13, 2078-2085.
41 J. Yang, M. G. Ma, C. C. Sun, Y. F. Zhang, W. Huang and X. C. Dong, J. Mater. Chem. A, 2014, 3, 1258-1264.

42 F. Zhang, Y. Y. Bao, S. S. Ma, L. Liu and X. Shi, J. Mater. Chem. A, 2017, 5, 7474-7481.

43 X. Li, J. P. Rong and B. Q. Wei, ACS Nano, 2010, 4, 6039-6049. 44 Z. K. Li, Y. Yao, Y. J. Zheng, T. T. Gao, Z. H. Liu and G. W. Zhou, J. Electrochem. Soc., 2018, 165, E58-E63.

45 L. Wei, M. Sevilla, A. B. Fuertes, R. Mokaya and G. Yushin, Adv. Energy Mater., 2010, 1, 356-361.

46 K. P. Wang and H. S. Teng, J. Electrochem. Soc., 2007, 154, A993-A998.

47 Y. Qian, R. Liu, Q. F. Wang, J. Xu, D. Chen and G. Z. Shen, J. Mater. Chem. A, 2014, 2, 10917-10922.

48 L. Li, Y. Q. Zhang, F. Shi, Y. J. Zhang, J. H. Zhang, C. D. Gu, X. L. Wang and J. P. Tu, ACS Appl. Mater. Interfaces, 2014, 6, 18040-18047.

49 M. C. Liu, J. J. Li, W. Han and L. Kang, J. Energy Chem., 2016, 25, 601-608. 